\title{
Assessment of the nitrogen fertilization effect on bioactive compounds of frozen fresh and dried samples of Stevia rebaudiana Bertoni
}

\author{
Marisa R. Barroso $^{\mathrm{a}, \mathrm{b}}$, Natália Martins ${ }^{\mathrm{a}}$, Lillian Barros ${ }^{\mathrm{a}, *}$, Amilcar L. Antonio ${ }^{\mathrm{a}}$, \\ M. Ângelo Rodrigues ${ }^{\mathrm{a}}$, Maria João Sousa ${ }^{\mathrm{a}}$, Celestino Santos-Buelga ${ }^{\mathrm{b}}$, Isabel C.F.R. Ferreira ${ }^{\mathrm{a}, *}$ \\ a Centro de Investigação de Montanha (CIMO), Instituto Politécnico de Bragança, Campus de Santa Apolónia, 5300-253 Bragança, Portugal \\ b Grupo de Investigación en Polifenoles (GIP-USAL), Facultad de Farmacia, Universidad de Salamanca, Campus Miguel de Unamuno s/n, 37007 Salamanca, Spain
}

\section{A R T I C L E I N F O}

\section{Keywords:}

Stevia rebaudiana Bertoni

Chemical composition

Phenolic compounds

Nitrogen fertilization

Antioxidant activity

\begin{abstract}
A B S T R A C T
The present study aims to assess the effect of different nitrogen $(\mathrm{N})$ rates on the chemical composition and antioxidant properties of stevia frozen fresh and dried leaves, and to define the best growing conditions to maximize the levels of bioactive compounds. In general, processing affects more significantly the tocopherol and sugar contents than $\mathrm{N}$ fertilization. The most abundant sugars were xylose, arabinose + fructose and sucrose, presenting dried samples with higher contents than frozen fresh ones, while the latter better retained tocopherols than dry samples. Regarding phenolic compounds, greater levels were found in dried samples and in those fertilized with $25 \mathrm{~kg} \mathrm{Nha}^{-1}$. Leaves from plants fertilized with 25 and $50 \mathrm{~kg} \mathrm{~N}^{-1}$ also evidenced higher antioxidant activity, which seemed to be influenced by the phenolic composition. In general, $\mathrm{N}$ fertilization provides an improvement in the chemical composition and bioactive potential of stevia leaves.
\end{abstract}

\section{Introduction}

Stevia rebaudiana Bertoni, widely known as Sweet-Leaf is an herbaceous perennial shrub, that occurs naturally in South America, but nowadays it is widely cultivated and mostly used as a sweetener in many parts of the world (Gupta, Purwar, Sundaram, \& Rai, 2013). The reason why this plant is being used as a source of natural sweetener is due to its high content in sweet diterpene glycosides, including isosteviol, stevioside, rebaudiosides (A, B, C, D, E and F), steviolbioside and dulcoside A (Goyal, Samsher, \& Samsher, 2010; Rajasekaran, Ramakrishna, Sankar, Giridhar, \& Ravishankar, 2008). The natural sweeteners of $S$. rebaudiana can be 300 times sweeter than sucrose (Gardana, Scaglianti, \& Simonetti, 2010). Beside glycosides, the leaves of stevia also contain other phytochemicals, such as flavonoids, phenolic acids, fatty acids, proteins and vitamins (Gupta et al., 2013). Several studies have reported that stevia extracts exert significant antimicrobial, anti-hypertensive, antitumor, anti-inflammatory, hepatoprotective and immunomodulatory activities, with those biological effects being closely related to its high abundance in bioactive phytoconstituents (Tadhani, Patel, \& Subhash, 2007; Yildiz-Ozturk, Nalbantsoy, Tag, \& Yesil-Celiktas, 2015; Álvarez-Robles, López-Orenes, Ferrer, \& Calderón, 2016).

It is known that the chemical and biological diversity of $S$. rebaudiana are influenced by several factors, like genotype, phenological stage and growth conditions (Brandle \& Rosa, 1992; Brandle, Starratt, \& Gijzen, 1998; Yadav, Singh, Dhyani, \& Ahuja, 2011). However, there is a lack of information about the real effects of fertilization on the chemical and bioactive properties of stevia plants. In fact, $\mathrm{N}$, phosphorous (P) and potassium (K) fertilization, as well as plant status, display an important role in defining the final concentration of secondary metabolites and, therefore, biological potential (Aires, Rosa, \& Carvalho, 2006). Among them, $\mathrm{N}$ is considered as being one of the most important essential elements in plant science, being used by plants to synthesize many organic compounds, such as amino acids, proteins, enzymes and nucleic acids (Koeduka et al., 2006). Beyond this, $\mathrm{N}$ also has other functions in plant life, such as those related with biomass yield (Rodrigues, Afonso, Ferreira, \& Arrobas, 2016); presently, it was confirmed that high rates of $\mathrm{N}$ increase both the number and size of leaf cells (Yadav et al., 2011). Regarding bioactive constituents, and despite the existence of conflicting results, it has been shown that $\mathrm{N}$ availability not only influences the secondary metabolites production in a predictable manner, but also plant growth and differentiation processes (Aires et al., 2006; Ibrahim, Jaafar, Rahmat, \& Rahman, 2011). Thus, it becomes increasingly evident that different $\mathrm{N}$ rates influence the biosynthesis of active constituents by cultivated medicinal plants (Karimi, Jaafar, \& Ahmad, 2013; Tavarini, Sgherri, Ranieri, \& Angelini, 2015). For example, Tavarini et al. (2015) observed that both $\mathrm{N}$ fertilization and harvest time exert a pronounced influence on

\footnotetext{
* Corresponding authors.

E-mail addresses: lillian@ipb.pt (L. Barros), iferreira@ipb.pt (I.C.F.R. Ferreira).
} 
phytochemical composition and antioxidant activity of stevia. A similar scenario was also observed in Labisia pumila (Benth. \& Hook) indicating that the manipulation of $\mathrm{N}$ fertilization levels may be an effective method to improve the expression of secondary metabolites (Ibrahim et al., 2011). However, in general, research is overlooking the fact that the availability of $\mathrm{N}$ might be a determinant/important factor on secondary metabolism in medicinal and aromatic plants.

Thus, and considering the importance of bioactive compounds in $S$. rebaudiana, the present study aims to assess the effect of different $\mathrm{N}$ rates on the chemical composition of stevia frozen fresh and dried leaves, and to define the best growing conditions to maximize the levels of these compounds.

\section{Materials and methods}

\subsection{Cultivation procedure, collection and treatment of the samples}

The field trial supporting this study was carried out in the Vilariça region (41.191373; - 7.103809), NE Portugal, which benefits from a Mediterranean climate. The mean annual temperature and accumulated precipitation in the period from 1971 to 2000 were, respectively, $14.3{ }^{\circ} \mathrm{C}$ and $509 \mathrm{~mm}$. The field trial was established in a Fluvisol, loam textured (16.1\% clay, $41.3 \%$ silt, $42.6 \%$ sand), $\mathrm{pH}\left(\mathrm{H}_{2} \mathrm{O}\right) 6.1$, organic carbon $9.9 \mathrm{~g} \mathrm{~kg}^{-1}$ and extractable (Egner-Rhiem) $\mathrm{P}\left(\mathrm{P}_{2} \mathrm{O}_{5}\right)$ and $\mathrm{K}\left(\mathrm{K}_{2} \mathrm{O}\right)$ at 39.5 and $240 \mathrm{mg} \mathrm{kg}^{-1}$, respectively. The field trial included four $\mathrm{N}$ rates [0 (N0), 25 (N1), $50(\mathrm{~N} 2), 100(\mathrm{~N} 3) \mathrm{kg} \mathrm{N} \mathrm{ha}^{-1}$ ] and was arranged as a completely randomized design, with three replications. $\mathrm{N}$ was supplied as an organic amendment containing 6\% N, 3\% P $\left(\mathrm{P}_{2} \mathrm{O}_{5}\right)$ and $2 \% \mathrm{~K}\left(\mathrm{~K}_{2} \mathrm{O}\right)$. A drip irrigation system was installed after soil preparation and covered with an anti-weed screen. Plants were grown in holes made in the screen spaced at $50 \times 40 \mathrm{~cm}$. The cuttings, previously rooted in a greenhouse, were planted on June 13 th 2014, and the harvest took place on August 5th 2014.

After collection, specimens were separated into two similar halves and placed in paper bags. Half of the samples were dried at $30^{\circ} \mathrm{C}$ (Memmert oven, Edelstahl Rostfrei, Germany) for six days, while the other half was immediately frozen and kept at $-20{ }^{\circ} \mathrm{C}$ for the same period before being lyophilized (FreeZone 4.5, Labconco, Kansas City, MO, USA). All the samples were reduced to a fine powder ( $\sim 20$ mesh) and stored in a desiccator protected from light for subsequent assays.

\subsection{Free sugars}

Free sugars were determined by HPLC coupled to a RI detector (Knauer, Smartline system 1000, Berlin, Germany) using the internal standard (IS, melezitose) method, as previously described by the authors (Barroso et al., 2016). Mobile phase consisted of acetonitrile:water mixture $(70: 30 \mathrm{v} / \mathrm{v}$, acetonitrile HPLC-grade, Lab-Scan, Lisbon, Portugal) and separation was achieved using a Eurospher 100-5 NH2 column $(4.6 \times 250 \mathrm{~mm}, 5 \mu \mathrm{m}$, Knauer). Results (Clarity 2.4 software, DataApex, Prague, Czech Republic) were expressed in $\mathrm{g}$ per $100 \mathrm{~g}$ of dry weight (dw).

\subsection{Tocopherols}

Tocopherols were determined following a procedure previously described by Barroso et al. (2016), using a HPLC system (Knauer, Smartline system 1000, Berlin, Germany) coupled to a fluorescence detector (FP-2020; Jasco, Easton, USA) programmed for excitation at $290 \mathrm{~nm}$ and emission at $330 \mathrm{~nm}$, using the IS (tocol, Matreya, Pleasant Gap, PA, USA) method for quantification. Mobile phase consisted of a mixture of hexane:ethyl acetate (70:30, v/v, hexane and ethyl acetate HPLC-grade, Lab-Scan, Lisbon, Portugal), and chromatographic separation was performed using a Polyamide II column $(250 \times 4.6 \mathrm{~mm}$, $5 \mu \mathrm{m}$; YMC, Kyoto, Japan). The results (Clarity 2.4 software, DataApex, Prague, Czech Republic) were expressed in $\mathrm{g}$ per $100 \mathrm{~g}$ of dw.

\subsection{Extract preparation}

Extracts were prepared by maceration with a stirring agitation at $150 \mathrm{rpm}$, using methanol:water $(80: 20, \mathrm{v} / \mathrm{v}, 30 \mathrm{ml})$ at $25^{\circ} \mathrm{C}$ for $1 \mathrm{~h}$, then, the samples were filtered (Whatman No. 4 paper), as previously described by Barroso et al. (2016). The residue was further re-extracted with an additional $30 \mathrm{ml}$ portion of the methanol:water $(80: 20, \mathrm{v} / \mathrm{v}$, $30 \mathrm{ml}$ ) mixture. The combined extracts were evaporated (Büchi R-210, Flawil, Switzerland) to remove the methanol, and the aqueous phase was lyophilized.

\subsection{Phenolic compounds}

The extracts were re-dissolved in methanol/water $(80: 20$, v/v, $5 \mathrm{mg} / \mathrm{ml}$ ) and filtered through a $0.22-\mu \mathrm{m}$ disposable LC filter disk for HPLC-DAD-ESI/Mn analysis. The chromatographic analysis was carried out in a Dionex Ultimate 3000 UPLC (Thermo Scientific, San Jose, CA, USA) system equipped with a diode array detector coupled to a mass spectrometer detector (LC-DAD-ESI/MSn) and an Xcalibur ${ }^{\circledast}$ data system. The extracts were filtered through a $0.22-\mu \mathrm{m}$ disposable LC filter disk before injection. The chromatographic separation was performed as previously described by Bessada, Barreira, Barros, Ferreira, and Oliveira (2016), using 280 and $370 \mathrm{~nm}$ as preferred wavelengths for UV detection. Mass spectrometry detection was performed in negative mode, using a Linear Ion Trap LTQ XL mass spectrometer (ThermoFinnigan, San Jose, CA, USA) equipped with an ESI source. Phenolic compounds were identified using the previous identifications made in our laboratory (Barroso et al., 2016). For quantitative analysis, a calibration curve for each available phenolic standard (Extrasynthèse, Genay, France) was constructed based on the area of the peaks recorded at $330 \mathrm{~nm}$ (hydroxycinnamoyl derivatives) or $370 \mathrm{~nm}$ (flavonols) and results were expressed in $\mathrm{mg} / \mathrm{g}$ of extract.

\subsection{Evaluation of in vitro antioxidant properties}

The extracts were re-dissolved in methanol/water $(80: 20, \mathrm{v} / \mathrm{v})$ at a final concentration of $5 \mathrm{mg} / \mathrm{ml}$ and further diluted at different concentrations to perform the distinct in vitro assays. The antioxidant potential was evaluated by the DPPH (2,2-diphenyl-1-picrylhydrazyl, Alfa Aesar, Ward Hill, MA, USA) radical-scavenging activity and reducing power (measured by ferricyanide Prussian blue assay), following a procedure previously described by Barroso et al. (2016). The results were expressed as the extract concentrations providing $50 \%$ of antioxidant activity or 0.5 of absorbance $\left(\mathrm{EC}_{50}\right)$, calculated from the graphs of antioxidant activity percentages (DPPH assay) or absorbance at $690 \mathrm{~nm}$ (reducing power assay) against extract concentrations. Trolox was used as a standard (Sigma-Aldrich, St. Louis, MO, USA).

\subsection{Statistical analysis}

The experimental data were checked for normality (Shapiro-Wilk test) and homogeneity of variances (Levene's test) assumptions. When it was not possible to apply an analysis of variance (ANOVA) and for data that did not follow a normal distribution, non-parametric tests were performed to evaluate significant differences at a level of 5\%, using the EXCEL software, Microsoft Office Professional Plus 2010, version 14.0.7159.5000, with the add-in Analysis ToolPak (Microsoft Corp., USA). For each factor, $\mathrm{N}$ or Process, the results were grouped regardless of process (frozen fresh or dried) and regardless each $\mathrm{N}$ content, respectively. For N, the results are presented as the mean value regardless of the process (frozen fresh or dried). For the Process, the results are presented as the mean value regardless of $\mathrm{N}$ content. The standard deviations presented in the tables should not be regarded as a measure of accuracy of the methodologies, since they include the results for one of the factors (Process or N). Furthermore, a Pearson's correlation analysis between the antioxidant activity and all the analysed 
compounds was carried out, with a 95\% confidence level, using IBM SPSS Statistics software, version 23.0. (IBM Corp., Armonk, New York, USA).

\section{Results and discussion}

\subsection{Free sugars and tocopherols composition}

Tables 1 and 2 show the results obtained for free sugars and tocopherols, respectively, in stevia frozen fresh and dried leaves. Concerning free sugar composition (Table 1), seven different compounds were identified in all the studied samples, namely rhamnose, xylose, arabinose + fructose, glucose, sucrose, trehalose and raffinose. The most abundant sugars were xylose, arabinose + fructose and sucrose. The total sugar content in the studied samples decreased with the level of $\mathrm{N}$ fertilization, N0 presented the highest content and N3 $\left(100 \mathrm{~kg} \mathrm{Nha}^{-1}\right)$ the lowest one. This is in agreement with the observations made by Ibrahim et al. (2011) regarding the effects of $\mathrm{N}$ fertilization on primary and secondary metabolites of three varieties of Labisia pumila Blume. Nevertheless, $\mathrm{N} 1\left(25 \mathrm{~kg} \mathrm{Nha}^{-1}\right)$ presented similar and not significantly different sugar contents as those of N0, so it could be considered a good compromise $\mathrm{N}$ level for fertilization.

Concerning the process conditions, dried samples presented statistically higher contents in sugars than frozen fresh samples, $13.54 \pm 0.53$ vs. $12.11 \pm 2.04 \mathrm{~g} / 100 \mathrm{~g}$, except for xylose.

Regarding tocopherol composition (Table 2), frozen fresh $S$. rebaudiana leaves revealed a significantly higher content than the dried samples. Thermal sensitivity of tocopherols to relatively high temperatures may explain the obtained results, leading to a consequent reduction of the tocopherol content. Actually, the same results were already obtained by the authors in a previous study on frozen fresh $(12.70 \pm 0.10 \mathrm{~g} / 100 \mathrm{~g})$ and oven-dried $(6.16 \pm 0.02 \mathrm{~g} / 100 \mathrm{~g})$ samples of $S$. rebaudiana leaves (Barroso et al., 2016). On the other hand, a direct correlation between the different $\mathrm{N}$ rates used for fertilization and tocopherol contents was not observed. Nevertheless, although the differences were not statistically significant, the highest concentrations of total tocopherols were found in the samples with higher levels of $\mathrm{N}$ fertilization (N2 and N3 samples). In general, comparing the obtained results for the composition of free sugars and tocopherols, it is possible to infer that the drying process exerts a higher impact on the levels of those components than $\mathrm{N}$ fertilization.

\subsection{Phenolic composition}

Table 3 presents the obtained results for the phenolic composition in stevia leaves. Eighteen phenolic compounds were detected, including ten flavonoids (namely quercetin and kaempferol glycosides) and eight hydroxycinnamoyl derivatives. All the identified phenolic compounds were previously described by Barroso et al. (2016) in stevia leaves. Caffeic acid derivatives were the most abundant phenolic compounds in all the tested samples, namely 5-O-caffeoylquinic and 3,5-O-dicaffeoylquinic acids (compounds 3 and 11). In relation to flavonoids, quercetin glycosides were more abundant than kaempferol glycosides, with quercetin-3-O-rhamnoside (14) and quercetin-3-O-glucoside (7) was the majority derivative.

Dried samples presented higher levels of phenolic compounds than frozen fresh ones (126.65 vs $85.17 \mathrm{mg} / \mathrm{g}$ extract), even though quercetin-3-O-rutinoside and quercetin-O-pentosyl-deoxyhexoside (compounds 6 and $\mathbf{9}$, respectively) were not detected in the dried samples. Moreover, kaempferol- $O$-hexoside (12) was not detected in the frozen fresh samples, and no statistically significant differences were found for compounds 10, 14 and 18 between frozen fresh and dry samples. The obtained results are in line with those previously reported (Barroso et al., 2016), where half the concentration of phenolic compounds was found in frozen fresh samples than in oven-dried samples of $S$. rebaudiana leaves.

N1 samples (fertilized with $25 \mathrm{~kg} \mathrm{Nha}^{-1}$ ) showed significantly higher contents of total phenolic compounds than the other compounds, as well as some individual molecules (i.e., compounds 7-9 and 11-18), compared to non-fertilized samples. This aspect may be directly correlated with sugar content (Table 1 ). In fact, samples with the highest abundance in phenolic compounds were also those that presented the highest levels of free sugars (i.e. dried processed samples, and N1 and control N0 samples). Similar findings were reported by

Table 1

Sugar content (g/100 g dry weight) in Stevia rebaudiana Bertoni leaves, under different N substrate rates and process (frozen fresh and dried).

\begin{tabular}{|c|c|c|c|c|c|c|c|c|c|}
\hline & & Rhamnose & Xylose & Arab. + Fruct. & Glucose & Sucrose & Trehalose & Raffinose & Total \\
\hline \multirow[t]{4}{*}{ Nitrogen } & No & $0.52 \pm 0.03 \mathrm{ab}$ & $6.79 \pm 3.11 \mathrm{ab}$ & $2.67 \pm 0.67 c$ & $0.15 \pm 0.12 \mathrm{a}$ & $3.02 \pm 1.30 \mathrm{ab}$ & $0.42 \pm 0.05 \mathrm{a}$ & $0.53 \pm 0.36 \mathrm{a}$ & $14.10 \pm 1.01 \mathrm{a}$ \\
\hline & N1 & $0.45 \pm 0.09 \mathrm{bc}$ & $4.52 \pm 0.50 \mathrm{a}$ & $4.10 \pm 0.24 \mathrm{a}$ & $0.05 \pm 0.04 \mathrm{~b}$ & $3.32 \pm 0.32 \mathrm{a}$ & $0.34 \pm 0.18 \mathrm{~b}$ & $0.60 \pm 0.51 \mathrm{a}$ & $13.39 \pm 0.78 \mathrm{ab}$ \\
\hline & N2 & $0.41 \pm 0.02 \mathrm{c}$ & $4.55 \pm 0.34 \mathrm{a}$ & $3.51 \pm 0.35 b$ & $0.06 \pm 0.03 \mathrm{~b}$ & $2.85 \pm 0.81 \mathrm{ab}$ & $0.26 \pm 0.06 \mathrm{c}$ & $0.63 \pm 0.46 \mathrm{a}$ & $12.26 \pm 1.92 \mathrm{bc}$ \\
\hline & N3 & $0.54 \pm 0.03 \mathrm{a}$ & $3.71 \pm 0.38 b$ & $3.83 \pm 0.41 \mathrm{a}$ & $0.04 \pm 0.04 \mathrm{~b}$ & $2.48 \pm 0.78 \mathrm{~b}$ & $0.27 \pm 0.05 b c$ & $0.59 \pm 0.37 \mathrm{a}$ & $11.46 \pm 1.79 c$ \\
\hline \multirow[t]{2}{*}{ Process } & Frozen fresh & $0.46 \pm 0.08 \mathrm{~A}$ & $5.73 \pm 2.41 \mathrm{~A}$ & $3.17 \pm 0.73 \mathrm{~B}$ & $0.13 \pm 0.08 \mathrm{~A}$ & $2.17 \pm 0.55 \mathrm{~B}$ & $0.29 \pm 0.11 \mathrm{~A}$ & $0.15 \pm 0.03 \mathrm{~B}$ & $12.11 \pm 2.04 \mathrm{~B}$ \\
\hline & Dried & $0.50 \pm 0.07 \mathrm{~A}$ & $4.17 \pm 0.42 \mathrm{~B}$ & $3.88 \pm 0.40 \mathrm{~A}$ & $0.02 \pm 0.02 \mathrm{~B}$ & $3.64 \pm 0.42 \mathrm{~A}$ & $0.33 \pm 0.05 \mathrm{~A}$ & $0.99 \pm 0.11 \mathrm{~A}$ & $13.54 \pm 0.53 \mathrm{~A}$ \\
\hline
\end{tabular}

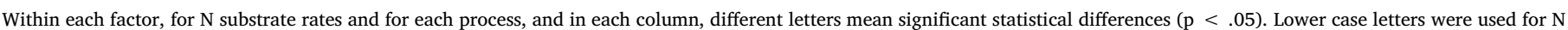
substrate rate parameters and capital letters were used for process.

Table 2

Tocopherol content (mg/100 g dry weight) in Stevia rebaudiana Bertoni leaves, under different N substrate rates and process (frozen fresh and dried).

\begin{tabular}{|c|c|c|c|c|c|}
\hline & & $\alpha$-tocopherol & $\gamma$-tocopherol & $\delta$-tocopherol & Total tocopherols \\
\hline \multirow[t]{4}{*}{ Nitrogen } & No & $9.04 \pm 3.52 \mathrm{a}$ & $0.21 \pm 0.01 \mathrm{a}$ & $0.18 \pm 0.08 \mathrm{~b}$ & $9.42 \pm 3.59 \mathrm{a}$ \\
\hline & N1 & $8.50 \pm 2.67 \mathrm{a}$ & $0.17 \pm 0.08 \mathrm{a}$ & $0.25 \pm 0.07 \mathrm{ab}$ & $8.92 \pm 2.81 \mathrm{a}$ \\
\hline & N2 & $9.66 \pm 3.15 \mathrm{a}$ & $0.18 \pm 0.08 \mathrm{a}$ & $0.43 \pm 0.22 \mathrm{a}$ & $10.27 \pm 3.45 \mathrm{a}$ \\
\hline & N3 & $9.08 \pm 2.82 \mathrm{a}$ & $0.17 \pm 0.10 \mathrm{a}$ & $0.50 \pm 0.30 \mathrm{a}$ & $9.75 \pm 3.22 \mathrm{a}$ \\
\hline \multirow[t]{2}{*}{ Process } & Frozen fresh & $11.84 \pm 0.66 \mathrm{~A}$ & $0.24 \pm 0.03 \mathrm{~A}$ & $0.49 \pm 0.23 \mathrm{~A}$ & $12.57 \pm 0.74 \mathrm{~A}$ \\
\hline & Dried & $6.30 \pm 0.39 \mathrm{~B}$ & $0.13 \pm 0.06 \mathrm{~B}$ & $0.19 \pm 0.05 \mathrm{~B}$ & $6.61 \pm 0.40 \mathrm{~B}$ \\
\hline
\end{tabular}

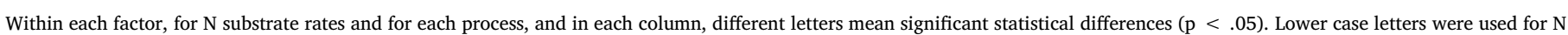
substrate rate parameters and capital letters were used for process 
Table 4

Antioxidant activity (expressed in $\mathrm{EC}_{50}$ values, $\mathrm{mg} / \mathrm{ml}$ ) of Stevia rebaudiana Bertoni leaves, under different $\mathrm{N}$ substrate rates and process (frozen fresh and dried).

\begin{tabular}{llll}
\hline & & DPPH scavenging activity & Reducing power \\
\hline Nitrogen & N0 & $36.76 \pm 14.59 \mathrm{ab}$ & $34.26 \pm 5.63 \mathrm{a}$ \\
& N1 & $40.82 \pm 10.45 \mathrm{a}$ & $31.21 \pm 1.63 \mathrm{~b}$ \\
& N2 & $30.06 \pm 4.33 \mathrm{~b}$ & $35.66 \pm 9.93 \mathrm{ab}$ \\
& N3 & $37.94 \pm 12.50 \mathrm{ab}$ & $32.14 \pm 6.43 \mathrm{ab}$ \\
Process & Frozen fresh & $46.40 \pm 7.57 \mathrm{~A}$ & $38.99 \pm 4.62 \mathrm{~A}$ \\
& Dried & $26.39 \pm 3.20 \mathrm{~B}$ & $27.64 \pm 1.83 \mathrm{~B}$ \\
\hline
\end{tabular}

Within each factor, for $\mathrm{N}$ substrate rates and for each process, and in each column different letters mean significant statistical differences $(p<.05)$. Lower case letters were used for $\mathrm{N}$ substrate rate parameters and capital letters were used for process.

Ibrahim et al. (2011), who suggested that high sugar content may exert a more pronounced influence on the synthesis and up regulation of secondary metabolites, and consequently increased total phenolic contents (in terms of both phenolic acids and flavonoids), as observed in the present study.

\subsection{Antioxidant activity}

Table 4 shows the results obtained in the assessment of the in vitro antioxidant potential of $S$. rebaudiana leaves, under different $\mathrm{N}$ substrate rates and process (fresh frozen and dried). Two different methods were used to determine the antioxidant activity of stevia samples, namely DPPH radical scavenging activity (RSA) and reducing power (RP). In general, dried samples revealed the best values $(\mathrm{RSA}=26.39 \pm 3.20 \mathrm{mg} / \mathrm{ml} ; \mathrm{RP}=27.64 \pm 1.83 \mathrm{mg} / \mathrm{ml})$. These results are also in agreement with those previously obtained (Barroso et al., 2016), in which oven-dried samples evidenced higher antioxidant capacity than frozen fresh samples.

$\mathrm{N} 2\left(\mathrm{EC}_{50}=30.06 \pm 4.33 \mathrm{mg} / \mathrm{ml}\right)$ and $\mathrm{N} 1\left(\mathrm{EC}_{50}=31.21 \pm 1.63 \mathrm{mg} /\right.$ $\mathrm{ml}$ ) samples presented the best results for RSA and RP, respectively, followed in each case by N0 and N3 samples. Thus, the measured antioxidant potential of stevia samples presented the following decreasing order: RSA: N2 $>$ N0 > N3 > N1; RP: N1 > N3 > N0 > N2. A positive correlation was found when comparing the results obtained for the antioxidant activity with the phenolic compound content. Samples with greater abundance in phenolic compounds (i.e., N1 and dried processed samples) were those that revealed the highest antioxidant activity. On the other hand, and in a general manner, dried samples were at the same time those that presented the highest antioxidant potential, content of free sugars and phenolic compounds, and the lowest values of tocopherols. On the contrary, samples containing the highest content in tocopherols (frozen fresh samples) were those that presented the lowest antioxidant potential and phenolic compound content. These observations suggest that the antioxidant ability of stevia samples is more closely influenced by phenolic compounds than by tocopherols, which would not determine the antioxidant capacity and possible health-promoting potential of stevia leaves. Concerning samples obtained under different $\mathrm{N}$ substrate rates, significant composition differences were observed between the studied samples (mainly in terms of sugars and phenolic compounds). Moreover, better values of antioxidant activity were obtained for fertilized samples (i.e., N2 for RSA, and N1 and N3 for RP) than for the non-fertilized one NO. In this sense, it seems that N fertilization might provide a considerable improvement on the bioactive potential of stevia leaves.

Correlation factors were obtained between the antioxidant activity assays and phenolic compounds (individual compounds and total content), using a Pearson's correlation analysis, because the normality was verified through a Shapiro-Wilk test. The correlation of all the antioxidant assays (DPPH scavenging activity and reducing power) and phenolic compounds are presented in Table 5 . In general, the majority of the compounds showed correlations statistically significant with the antioxidant activity assays. Quercetin-3-O-rutinoside (compound 6) 
Table 5

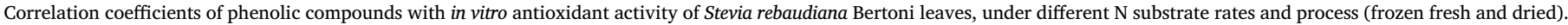

\begin{tabular}{|c|c|c|c|c|c|}
\hline \multirow[t]{2}{*}{ Peaks } & \multirow[t]{2}{*}{ Compounds } & \multicolumn{2}{|c|}{ DPPH scavenging activity } & \multicolumn{2}{|l|}{ Reducing power } \\
\hline & & Correlation factor & p-value & Correlation factor & p-value \\
\hline 1 & 3-O-Caffeoylquinic acid & -0.716 & $<.001$ & -0.688 & $<.001$ \\
\hline 2 & 4-O-Caffeoylquinic acid & -0.834 & $<.001$ & -0.759 & $<.001$ \\
\hline 3 & 5-O-Caffeoylquinic acid & -0.860 & $<.001$ & -0.815 & $<.001$ \\
\hline 4 & Caffeoyl-2,7-anhydro-3-deoxy-2-octulopyranosonic acid & -0.807 & $<.001$ & -0.746 & $<.001$ \\
\hline 5 & Caffeic acid derivative & -0.891 & $<.001$ & -0.840 & $<.001$ \\
\hline 6 & Quercetin-3-O-rutinoside & 0.989 & $<.001$ & 0.944 & $<.001$ \\
\hline 7 & Quercetin-3-O-glucoside & -0.606 & .002 & -0.617 & .001 \\
\hline 8 & 3,4-O-Dicaffeoylquinic acid & -0.894 & $<.001$ & -0.853 & $<.001$ \\
\hline 9 & Quercetin-O-pentosyl-deoxyhexoside & -0.872 & .008 & -0.806 & .002 \\
\hline 10 & Kaempferol-3-O-glucoside & 0.538 & .021 & 0.526 & .025 \\
\hline 11 & 3,5-O-Dicaffeoylquinic acid & -0.794 & $<.001$ & 0.740 & $<.001$ \\
\hline 12 & Kaempferol-O-hexoside & 0.891 & $<.001$ & 0.852 & $<0.001$ \\
\hline 13 & Quercetin-3-O-xyloside & -0.719 & .008 & -0.616 & .033 \\
\hline 14 & Quercetin-3-O-rhamnoside & -0.189 & .377 & -0.194 & .364 \\
\hline 15 & 4,5-O-Dicaffeoylquinic acid & -0.809 & $<.001$ & -0.794 & $<.001$ \\
\hline 16 & Kaempferol-O-pentoside & 0.921 & $<.001$ & 0.713 & $<.001$ \\
\hline 17 & Kaempferol-O-pentoside & -0.078 & .759 & -0.176 & .486 \\
\hline \multirow[t]{4}{*}{18} & Kaempferol-O-deoxyhexoside & 0.143 & .572 & 0.217 & .388 \\
\hline & Total phenolic acids & -0.925 & $<.001$ & -0.872 & $<.001$ \\
\hline & Total flavonoids & -0.694 & .017 & -0.690 & .019 \\
\hline & Total phenolic compounds & -0.807 & $<.001$ & -0.768 & $<.001$ \\
\hline
\end{tabular}

presented the most significant correlation with all antioxidant activities tested. Nonetheless, the total flavonoid content was less strongly correlated with the antioxidant activity in comparison with the total phenolic acids, which could be due to its higher concentration present in the samples. The total phenolic compounds also presented an excellent correlation factor. With the exception of quercetin-3-O-rhamnoside, kaempferol-O-pentoside and kaempferol-O-deoxyhexoside (compounds 14, 17 and 18), which were the only compounds that did not present a statistically significant correlation with the antioxidant assays, presenting $p$-value $>.05$, all the remaining compounds presented good correlation factors. The major individual phenolic compound (5-O-caffeoylquinic acid) also had a high correlation with the antioxidant activity assays, showing a variation between -0.860 and -0.815 . Overall, total phenolic acids and total phenolic compounds showed statistically significant correlations with both the assays, displaying $p$-values $\leq .05$.

\section{Conclusion}

Considering all the obtained results, it is possible to conclude that the drying process exerts a higher impact on the chemical content than $\mathrm{N}$ fertilization. Dried samples were those that presented statistically higher contents in free sugars and phenolic compounds than frozen fresh samples, while frozen fresh samples revealed a higher content of tocopherols. Moreover, stevia samples with the highest abundance in phenolic compounds and free sugars (i.e. dried processed samples, and $\mathrm{N} 1$ and control N0 samples), with the lowest levels of tocopherols, were also those that revealed the highest antioxidant potential. Therefore, it seems that the antioxidant activity of stevia leaves is more closely determined by phenolic compounds content than tocopherols. Furthermore, correlation factors were determined between the antioxidant activity and the phenolic compounds, which revealed a high correlation with most of the individual compounds, along with the total phenolic acids and total phenolic compounds. Thus, the present findings regarding cultivation practices and how they can affect the quality and chemical composition of stevia leaves, may provide considerable insights for their upcoming use for health-promoting purposes.

\section{Acknowledgements}

The authors are grateful to the Foundation for Science and Technology (FCT, Portugal) and FEDER under Programme PT2020 for financial support to CIMO (UID/AGR/00690/2013) and to L. Barros contract. The authors are also grateful to the Interreg España-Portugal for financial support through the project 0377_Iberphenol_6_E. The GIPUSAL is financially supported by the Spanish Government through the project AGL2015-64522-C2-2-R.

\section{References}

Aires, A., Rosa, E., \& Carvalho, R. (2006). Effect of nitrogen and sulfur fertilization on glucosinolates in the leaves and roots of broccoli sprouts (Brassica oleracea var. italica). Journal of the Science of Food and Agriculture, 86, 1512-1516. http://dx.doi. org/10.1002/jsfa.2535.

Álvarez-Robles, M. J., López-Orenes, A., Ferrer, M. A., \& Calderón, A. A. (2016). Methanol elicits the accumulation of bioactive steviol glycosides and phenolics in Stevia rebaudiana shoot cultures. Industrial Crops and Products, 87, 273-279. http://dx.doi. org/10.1016/j.indcrop.2016.04.054.

Barroso, M., Barros, L., Rodrigues, M.Â., Sousa, M. J., Santos-Buelga, C., \& Ferreira, I. C. F. R. (2016). Stevia rebaudiana Bertoni cultivated in Portugal : A prospective study of its antioxidant potential in different conservation conditions. Industrial Crops and Products, 90, 49-55. http://dx.doi.org/10.1016/j.indcrop.2016.06.013.

Bessada, S. M., Barreira, J. C. M., Barros, L., Ferreira, I. C. F. R., \& Oliveira, M. B. P. P. (2016). Phenolic profile and antioxidant activity of Coleostephus myconis (L.) Rchb. f.: An underexploited and highly disseminated species. Industrial Crops and Products, $89,45-51$.

Brandle, J., \& Rosa, N. (1992). Heritabilrty for yield, leaf: Stem ratio and stevioside content estimated from a landrace cultivar of Stevia rebaudiana. Canadian Journal of Plant Science, 72, 1263-1266.

Brandle, J. E., Starratt, A. N., \& Gijzen, M. (1998). Stevia rebaudiana: Its agricultural, biological, and chemical properties. Canadian Journal of Plant Science, 78(4), 527-536. http://dx.doi.org/10.4141/P97-114.

Gardana, C., Scaglianti, M., \& Simonetti, P. (2010). Evaluation of steviol and its glycosides in Stevia rebaudiana leaves and commercial sweetener by ultra-high-performance liquid chromatography-mass spectrometry. Journal of Chromatography A, 1217(9), 1463-1470. http://dx.doi.org/10.1016/j.chroma.2009.12.036.

Goyal, S. K., Samsher, \& Samsher, R. K. (2010). Stevia (Stevia rebaudiana) a bio-sweetener: A review. International Journal of Food Sciences and Nutrition, 61(1), 1-10. http://dx. doi.org/10.3109/09637480903193049.

Gupta, E., Purwar, S., Sundaram, S., \& Rai, G. K. (2013). Nutritional and therapeutic values of Stevia rebaudiana: A review. Journal of Medicinal Plant Research, 7(46), 3343-3353. http://dx.doi.org/10.5897/JMPR2013.5276.

Ibrahim, M. H., Jaafar, H. Z. E., Rahmat, A., \& Rahman, Z. A. (2011). Effects of nitrogen fertilization on synthesis of primary and secondary metabolites in three varieties of kacip fatimah (Labisia pumila Blume). International Journal of Molecular Sciences, 
12(8), 5238-5254. http://dx.doi.org/10.3390/ijms12085238.

Karimi, E., Jaafar, H. Z. E., \& Ahmad, S. (2013). Antifungal, anti-inflammatory and cytotoxicity activities of three varieties of Labisia pumila Benth: From microwave obtained extracts. BMC Complementary and Alternative Medicine, 13(20), 1-10.

Koeduka, T., Fridman, E., Gang, D. R., Vassão, D. G., Jackson, B. L., Kish, C. M., ... Pichersky, E. (2006). Eugenol and isoeugenol, characteristic aromatic constituents of spices, are biosynthesized via reduction of a coniferyl alcohol ester. Proceedings of the National Academy of Sciences of the United States of America, 103(26), 10128-10133. http://dx.doi.org/10.1073/pnas.0603732103.

Rajasekaran, T., Ramakrishna, A., Sankar, K. U., Giridhar, P., \& Ravishankar, G. A. (2008). Analysis of predominant steviosides in Stevia rebaudiana Bertoni by liquid chromatography/electrospray ionization-mass spectrometry. Food Biotechnology, 22(2), 179-188. http://dx.doi.org/10.1080/08905430802043255.

Rodrigues, M. A., Afonso, S., Ferreira, I. Q., \& Arrobas, M. (2016). Response of stevia to nitrogen fertilization and harvesting regime in northeastern Portugal. Archives of Agronomy and Soil Science, 1-12. http://dx.doi.org/10.1080/03650340.2016.
1230272.

Tadhani, M. B., Patel, V. H., \& Subhash, R. (2007). In vitro antioxidant activities of Stevia rebaudiana leaves and callus. Journal of Food Composition and Analysis, 20(3-4), 323-329. http://dx.doi.org/10.1016/j.jfca.2006.08.004.

Tavarini, S., Sgherri, C., Ranieri, A. M., \& Angelini, L. G. (2015). Effect of nitrogen fertilization and harvest time on steviol glycosides, flavonoid composition, and antioxidant properties in Stevia rebaudiana Bertoni. Journal of Agricultural and Food Chemistry, 63(31), 7041-7050. http://dx.doi.org/10.1021/acs.jafc.5b02147.

Yadav, A. K., Singh, S., Dhyani, D., \& Ahuja, P. S. (2011). A review on the improvement of stevia [Stevia rebaudiana (Bertoni)]. Canadian Journal of Plant Science, 91(1), 1-27. http://dx.doi.org/10.4141/cjps10086.

Yildiz-Ozturk, E., Nalbantsoy, A., Tag, O., \& Yesil-Celiktas, O. (2015). A comparative study on extraction processes of Stevia rebaudiana leaves with emphasis on antioxidant, cytotoxic and nitric oxide inhibition activities. Industrial Crops and Products, 77, 961-971. http://dx.doi.org/10.1016/j.indcrop.2015.10.010. 